\title{
El papel de las mujeres socialistas en los organismos internacionales durante los años treinta*
}

\author{
Pilar Domínguez Prats ${ }^{1}$ \\ Universidad de Las Palmas de Gran Canaria
}

RESUMEN: El artículo analiza la presencia de las mujeres del sindicato socialista UGT en los organismos internacionales del periodo de entreguerras, la OIT, la SDN y la FSI, en especial durante la II República española, explicando las posturas de la UGT y sus representantes femeninas en esos foros. La base del trabajo son los documentos del Archivo del Instituto de Historia Social de Ámsterdam relativos a la Federación Socialista Internacional, completada con la generada por el PSOE y la UGT durante el periodo. El debate en torno al papel de las mujeres en el mercado de trabajo, que enfrentaba las posturas proteccionistas mayoritarias con las defensoras de la igualdad de derechos entre hombres y mujeres, marca la participación de las socialistas en estos foros internacionales a partir de la II República. Sus intervenciones fueron reducidas, dadas las limitaciones impuestas por el modelo de género de la domesticidad y por su cualificación. Las más destacadas representantes femeninas españolas en la SDN, la OIT y la FSI, Claudina García, Isabel de Palencia y Regina García, defendieron posturas contrapuestas en esos foros.

\footnotetext{
* Este artículo ha sido elaborado en el marco del proyecto de I + D, HAR2013-44849-P, «La trayectoria internacional del sindicalismo socialista español (1888-1986)», del Ministerio de Economía y Competitividad de España, del Programa Estatal de Investigación Científica y Técnica de Excelencia, concedido a la Fundación Francisco Largo Caballero.

Archivos consultados: Fundación Pablo Iglesias, Alcalá de Henares, Madrid, (FPI), fondos: Archivo Amaro Rosal Díaz (AARD), Archivo Histórico (AH).

Centro Documental de la Memoria Histórica (CDMH), fondos: Archivo Político-Social, Madrid; Archivo Tribunal de Responsabilidades Políticas, Madrid; y Archivo Ángel Galarza, Madrid.

International Institut of Social History, Ámsterdam (IISH), fondo: International Federation of Trade Unions (IFTU).

1 dominguezprats@gmail.com, ORCID iD: https://orcid.org/0000-0002-8829-2508. 


\title{
PAlabras ClaVE: OIT; FSI; trabajo femenino; Claudina García; Regina García; feminismo internacional.
}

The role played by socialist women in international organizations in the Thirties

\begin{abstract}
The article analyses the role played by women in the Spanish Socialist Union, UGT in international organizations (ILO, League of Nations, IFTU) during the interwar period, and in particular the years of the Second Spanish Republic. We explain the stances defended by female representatives of UGT in these forums. The work is based on documents taken from the Archive of the International Institute of Social History in Amsterdam and the documentation produced by the Spanish Socialist Party, $P S O E$, and UGT during that time. Socialist women's participation in these international forums during the Republic is defined by two conflicting stances on the debate about women's role in the labour market: a majority upheld a protectionist position, while feminist groups defended the equality between women and men in all areas. Owing to a gendered model of domesticity and their qualifications, these Spanish women could make only a limited contribution to the international debate. Claudina Garcia, Isabel de Palencia and Regina Garcia, the most notable Spanish Socialist women in the LN, ILO and IFTU, advocated differing positions in these debates.
\end{abstract}

KEY WORDS: ILO; IFTU; women's work; Claudina García; Regina García; international feminism.

CÓMO CITAR ESTE ARTÍCULO/CITATION: Domínguez Prats, Pilar, «El papel de las mujeres socialistas en los organismos internacionales durante los años treinta», Hispania, 78/259 (Madrid, 2018): 353-376. https://doi.org/10.3989/hispania.2018.009.

\section{LA FSI Y LA UGT FRENTE AL TRABAJO FEMENINO (1919-1931)}

El Tratado de Versalles, que ponía las bases del nuevo orden internacional tras la Gran Guerra, ligaba el destino de la nueva Oficina Internacional del Trabajo (OIT) a la recién creada Sociedad de las Naciones (SDN). Así, en el artículo 392 del tratado establecía que la OIT «formará parte del conjunto de las instituciones de la sociedad». Ginebra, ya elegida como sede de la Sociedad de Naciones, se convirtió también en la sede de la Oficina Internacional del Trabajo ${ }^{2}$; los temas de discusión de la Oficina de Trabajo, como se denominaba con frecuencia a la OIT, fueron a menudo objeto de discusión en la SDN.

La Federación Sindical Internacional (FSI) era una institución de carácter socialista e internacional reconstruida en 1919; desde ese momento se mostró

\footnotetext{
2 En http://www.ilo.org/90.
} 
muy interesada en aprovechar las oportunidades que brindaban las nuevas instituciones - en especial la OIT_- para promover una legislación internacional del trabajo que sirviera de base a las legislaciones de los Estados nacionales $^{3}$.

En el período de entreguerras la UGT participó en todos estos organismos supranacionales. La línea oficial del sindicato socialista español, desarrollada por Largo Caballero, tomaría el camino reformista, aunque enseguida su participación en los nuevos foros internacionales se convirtió en un tema muy controvertido para los socialistas, ya que para los más radicales - seguidores del modelo de la revolución rusa y luego de la III Internacional-, pertenecer a esas instituciones, tachadas de «burguesas», constituía un grave error para el movimiento obrero ${ }^{4}$.

Sin embargo, la pertenencia de la UGT a la SDN, la FSI y la OIT fue también una oportunidad para que las sindicalistas irrumpieran en la escena pública, ya que las mujeres estaban prácticamente ausentes de los organismos creados en el ámbito internacional y tampoco eran visibles en los altos puestos de los sindicatos nacionales. La Primera Conferencia de la OIT, convocada en octubre de 1919 en Washington, fue la ocasión propicia para impulsar la organización de un Congreso Internacional de Trabajadoras, y «por vez primera un foro internacional compuesto únicamente por mujeres pudo discutir sobre cuestiones relacionadas con la posición de la mujer en el derecho del trabajo» ${ }^{5}$. Las norteamericanas de la Women Trade Union League fueron las principales organizadoras de aquel congreso femenino, que consiguió reunir en octubre de 1919 a mujeres de diecinueve países, unas como delegadas oficiales y otras como invitadas, como fue el caso de España.

La Conferencia de la OIT en Washington discutió sobre la situación de las trabajadoras, de acuerdo con las recomendaciones de la Conferencia de mujeres que se había producido poco antes. Lo hizo en torno a dos temas principales: el primero, la protección de la maternidad de las trabajadoras, sobre la cual había un acuerdo general, aunque no se concretaba la forma de llevarla a cabo. El segundo y más controvertido fue la legislación sobre el trabajo nocturno de la mujer, tema que seguirá siendo objeto de discusión durante el período de entreguerras.

La postura de los sindicatos nacionales respecto al trabajo remunerado de las mujeres que se defendió en la OIT se alejaba de los planteamientos igualitarios del feminismo, que fueron sustentados por una minoría de delegadas estadounidenses y las francesas en particular. Ellas defendían la necesidad de establecer las mismas leyes para las mujeres que para los hombres y el acceso

3 VAN GOETHEM: 2006a.

4 AROCA, 38 (Roma, 2016): 9-33. BERZAL, 38 (Roma, 2016): 34-57.

5 VAN GOETHEM, 2006b: 279-290. 
a los mismos salarios, lo cual significaba, entre otras cosas, permitir el trabajo femenino nocturno ${ }^{6}$.

Se tiene constancia de la aparición de un «lobby internacional de mujeres» - como lo denomina Catherine Jacques_-, dentro de la Federación Sindical, igual que existía en la Sociedad de Naciones y en la OIT, donde hubo una representación del Consejo Internacional Feminista; esta era la asociación internacional más antigua - creada en 1888-, que funcionó durante todo el período de entreguerras con la belga Louisse Van Eeghen como representante feminista en esos organismos ${ }^{7}$.

De hecho, en aquellos foros internacionales se hizo patente la existencia de una postura feminista, en competencia con la mayoría de los hombres y mujeres sindicalistas que rechazaban la equiparación de derechos entre ambos sexos planteada por las asociaciones del denominado «feminismo burgués». Uno de los principales asuntos en los que se manifestó la controversia entre ambas posturas fue el de la nacionalidad de la mujer casada, ligada a la cuestión de los derechos de ciudadanía de las mujeres. El principio de igualdad entre mujeres y hombres se había quebrado en este punto durante la Gran Guerra, cuando muchas mujeres casadas habían perdido su nacionalidad de origen en beneficio de la de su marido. Contra ello se posicionaron las cuatro asociaciones feministas internacionales activas en el período de entreguerras; estas eran la Alianza Internacional por el Sufragio de las Mujeres, fundada en 1904 y el Consejo Internacional Feminista, defensoras ambas de un feminismo moderado, y la Inter-American Commission of Women (1928) y la Equal Right International (1930), más radicales ${ }^{8}$. De esta manera estos grupos se convierten en «actores transnacionales» dentro de la Sociedad de Naciones y la OIT.

Sin embargo, el sentir mayoritario era adoptar resoluciones a favor de una legislación protectora para las mujeres en el mercado laboral, siguiendo la posición que había dominado entre los sindicatos socialistas desde finales del siglo XIX ${ }^{9}$. Subyacía en esa postura la concepción dominante de los roles de género, según la cual las mujeres eran seres débiles necesitados de protección en su acceso al mercado laboral, en especial por su papel maternal. Así, las agrupaciones sindicales (masculinas en su mayoría) justificaban que los ingresos femeninos fueran menores basándose en la reivindicación de un salario familiar para el hombre, teniendo en cuenta su papel de breadwinner, es decir, de proveedor principal de recursos para la familia.

En contraposición, el trabajo remunerado femenino fuera del hogar era considerado algo secundario y pernicioso, pues provocaba el desorden fami-

6 VAN GOETHEM, 2006b: 286.

7 En este tema seguimos a JACQUES, 2006: 267-277.

8 JACQUES, 2006: 268.

9 NIELFA, 2003: 39-53. 
liar, dado que sacaba a la mujer de su lugar natural, donde debía ejercer como madre y ama de casa. Además los sindicatos veían a las trabajadoras como unas competidoras desleales por sus bajos salarios; de ahí que — si no podían expulsarlas-, la petición sindical, recogida también en los foros internacionales, era la igualdad salarial entre mujeres y hombres que eliminara esa competencia.

Siguiendo esta línea argumental sobre el trabajo femenino, los trascendentales convenios rubricados en Washington exigían a los países firmantes una legislación que incluyera:

La prohibición del trabajo nocturno para las mujeres, la limitación de la semana laboral, la prohibición del trabajo en industrias peligrosas e insalubres y las diez semanas de permiso de maternidad ${ }^{10}$.

En torno a estos temas girarán las discusiones a lo largo del período de entreguerras, en una lucha a favor y en contra de esas normas proteccionistas hacia las trabajadoras.

Desde el punto de vista organizativo aparecen en Washington las primeras organizaciones sindicales femeninas de ámbito internacional de este período, con la creación de la Federación Internacional de Trabajadoras (FIT). Esta declaraba como propósito «unir a las trabajadoras organizadas para tratar de mejorar el nivel de vida de las trabajadoras del mundo». En la reunión de la Federación Internacional de Trabajadoras celebrada en Colonia del 14 al 21 de agosto de 1923 se fijan tres objetivos más concretos, que insistían en los planteamientos anteriores, considerando los asuntos laborales de las mujeres junto a los de la infancia:

1. Promover la afiliación sindical entre las mujeres trabajadoras.

2. Examinar los proyectos legislativos propuestos por la OIT respecto al trabajo femenino para desarrollar una política internacional referente a las necesidades de mujeres y niños.

3. Promover la designación de mujeres en todos los comités y organizaciones que afecten al bienestar de los trabajadores ${ }^{11}$.

La FIT tuvo poco tiempo para luchar por estos objetivos, pues su primera reunión tuvo lugar en Ginebra, en $1921^{12}$ y la última en 1924, donde hubo otra reunión en 1923; en esa fecha el Comité Ejecutivo femenino de la FIT lo integraban mujeres de los países europeos que contaban con el mayor número

10 VAN GOETHEM, 2006b: 281.

11 International Congress of Working Women, Koln, IISH, 2137, IFTU (traducción propia).

12 The International Congress of Working women at Geneva. (October 17th-25th, 1921), IIHS, Int 2053/6, IFTU. 
de mujeres sindicadas; estos eran Bélgica, Inglaterra, Francia e Italia. La presidenta era entonces la belga Helene Burniaux y había tres vicepresidentas, la inglesa Margaret Bondfield, la francesa Jeanne Chevenard y la italiana L. Cassartelli ${ }^{13}$.

En la siguiente reunión de Viena (1924), la Federación Internacional de Trabajadoras tuvo representación por última vez, ya que la FSI la declaró disuelta a partir de entonces. En opinión de Van Goethem ${ }^{14}$, ello fue debido a los vaivenes políticos y financieros de la Federación Sindical Internacional, pues la Federación de las Trabajadoras dependía económicamente de las centrales sindicales nacionales, quienes decidieron no seguir financiando sus encuentros.

En su lugar se promovió la organización de un Comité Internacional de Mujeres Sindicalistas que aconsejaría al buró de la FSI en las cuestiones relativas a las mujeres, pues el buró carecía de representantes femeninas. Esta decisión indica la escasa atención que merecían las demandas femeninas para los dirigentes de la Federación Sindical Internacional, quienes quizás estaban preocupados por la aparición de un lobby internacional de mujeres dentro de la FSI, similar al que existía en la SDN, por lo que prefirieron disolver la Federación Internacional de Trabajadoras.

En 1927 la FSI celebró en París la Conferencia Internacional de Mujeres de los sindicatos afiliados a ella, pero no tenemos noticias acerca de la presencia española en ese evento al que asistieron 52 delegadas femeninas de 13 países ${ }^{15}$.

La UGT se vio obligada a tomar posiciones respecto a las cuestiones «femeninas» a remolque de los acontecimientos y de las demandas de la Federación Sindical Internacional, sin que tengamos constancia de que asistiera ninguna sindicalista española a las reuniones de la Sindical Internacional o de la Federación Internacional de Trabajadoras antes de 1931.

El sindicato se fue definiendo partiendo de su rechazo a las posturas igualitarias del feminismo, que tenía como antecedente lo ocurrido en relación con los grupos femeninos. En 1906 las militantes socialistas y de UGT habían formado las Agrupaciones de Mujeres Socialistas, pero estas habían sido disueltas en 1927 por diversos motivos ${ }^{16}$. Ante la petición de resucitarlas por parte de algunas militantes, como las hermanas Claudina y Luz García, el PSOE esgrimió el argumento de que entendía la afiliación segregada como «un obstáculo a la modernización», considerando que todos los militantes

13 Working women in many countries. Report of Congress, held at Vienna, August 1923, IIHS, Int 2053/14, IFTU.

14 VAN GOETHEM, 2006a.

15 L'Oeuvre de la FSI (1927-1930), IIHS, IFTU, 1930.

16 DEL MORAL, 27/2-3 (2014): 203-216. 
debían tener los mismos derechos y deberes sin distinción de sexos ${ }^{17}$. Curiosamente esa posición igualitaria no era defendida por los socialistas en los foros internacionales, donde abogaban por una legislación proteccionista para las mujeres trabajadoras.

En relación con esos foros y la «cuestión femenina», la documentación existente se remonta a diciembre de 1929, cuando un acta de la Comisión Ejecutiva de la UGT nos informa de que se estaba preparando un Congreso de la FSI en Estocolmo para el año 1931, en la que se planteaba si «debe convocarse una Conferencia especial de mujeres del mismo modo que se hizo cuando el Congreso de Viena».

Entonces, el sindicato socialista tuvo que definirse en torno al controvertido tema de la representación femenina en la FSI. Seguramente, por parte de algunas sindicalistas europeas o norteamericanas había interés en constituir de nuevo grupos sindicales femeninos y resucitar así la Federación Internacional de Trabajadoras, pues la petición se hace:

En vista de la poca representación que se da a las mujeres en las delegaciones obreras que asisten a los congresos de la FSI (...). Pide se le dé la opinión antes del 20 de enero ${ }^{18}$.

La Ejecutiva de UGT no mostró interés por reunir aparte a las mujeres en los congresos de la FSI y resolvió de forma rápida la petición de la Internacional Sindical. En el acta de la reunión figura que se acordó «no mandar a mujeres». En el mismo sentido se pronunciaba UGT un año más tarde, en la reunión de la Ejecutiva del 22 de enero de 1931; entonces la FSI preguntaba si se juzga útil reunir al Comité Internacional de Trabajadoras en 1931, pero la Ejecutiva se decantaba de nuevo por la opción que no implicaba reunir sólo a las mujeres: «dado que no tenemos organización femenina, se acuerda no intervenir en la proyectada Conferencia [Internacional] $\gg^{19}$.

Esta respuesta tan contundente deja claro que la creación de un Grupo Sindical Femenino a nivel internacional o nacional no estaba entre las preocupaciones del sindicato socialista español. La pasada experiencia de la Agrupación Socialista de Mujeres Madrileñas y la trayectoria de sus afiliadas tuvo gran trascendencia para la incorporación de las socialistas a la escena política internacional. El grupo femenino madrileño llegó a contar con 587 afiliadas

17 DEL MORAL, 27/2-3 (2014): 214. Las defensoras de una Agrupación Femenina en Madrid propusieron en 1930 que esta fuera restablecida, idea rechazada por la Ejecutiva del PSOE.

18 Acta de la reunión de la Comisión Ejecutiva de UGT, 19 de diciembre de 1929, FPI, AARD, 255-1.

19 Acta de la reunión de la Comisión Ejecutiva de UGT, 22 de enero de 1931, FPI, AARD, 255-2: 15. 
desde 1906 hasta el fin de su actividad, en 1927. Marta del Moral ${ }^{20}$ destaca como ya en las dos primeras décadas del siglo la mayoría - en concreto un $70 \%$ - de las que pertenecían a la Agrupación sabían leer y escribir, frente a una alta tasa de analfabetismo femenino en España ${ }^{21}$. Sin embargo, la militancia femenina en el PSOE y por tanto en UGT era todavía muy reducida en las primeras décadas del siglo XX, de ahí el lento desarrollo del sindicalismo $\mathrm{y}$ de las organizaciones femeninas de corte socialista.

\section{LAS SOCIALISTAS ESPAÑOLAS IRRUMPEN EN LA ESCENA INTERNACIONAL}

La llegada de la II República hará cambiar el modo de proceder del sindicato socialista respecto a la representación femenina en los organismos internacionales, siempre a remolque de sus peticiones.

Como ya ha sido puesto de manifiesto en numerosas ocasiones por las investigaciones realizadas ${ }^{22}$, la nueva república fue un período de gran desarrollo de la participación femenina en la esfera pública, gracias - entre otros factores--, a los derechos ciudadanos que les otorgaba la Constitución, como era la posibilidad de ejercer cargos públicos en condiciones de igualdad con el hombre, aboliendo las discriminaciones legales de todo tipo, laborales, penales o civiles por razón de sexo que lo impedían (artículo 40). También hay que considerar que en 1931 había mujeres socialistas con una trayectoria política o profesional que hizo posible su incorporación a estos foros internacionales o al Parlamento, como Victoria Kent, Clara Campoamor o Isabel de Palencia; pero es en el período republicano cuando el PSOE, igual que ocurría con el resto de los partidos políticos, empezó a tener en cuenta a las mujeres como ciudadanas depositarias de derechos políticos.

En el primer bienio republicano se incorporaron al PSOE mujeres que procedían de ambientes republicanos y del llamado «feminismo burgués», lo cual va a ser otra aportación clave a la representación femenina en la escena política internacional, que refuerza la presencia de aquellas procedentes de la antigua Agrupación Socialista de Mujeres de Madrid. Pocos meses después del 14 de abril, en junio de 1931, encontramos en la XV Conferencia Internacional del Trabajo en Ginebra a las dos primeras protagonistas: Isabel Oyarzábal Smith y Regina García García. Ambas representaban a la nueva República en la OIT. Isabel, nombrada «consejero», representaba al gobierno provi-

20 Para este tema seguimos a DEL MORAL, 27/2-3 (2014): 203-216.

21 La tasa de analfabetismo en 1930 era de un 40\% entre las mujeres mayores de 10 años frente a un 24\% entre los hombres de la misma edad, VILANOVA Y MORENO, 1992: 70.

22 Sobre este tema hay numerosos estudios, entre otros: AGUADO, 2005. DI FEBO, 2009: 129-146. NASH, 2009. DOMÍNGUEZ, 2009. 
sional de la República y Regina, como «asesor técnico», era la delegada por la UGT.

La aparición en la escena pública internacional de una representante del sindicato puede atribuirse a los requerimientos de la propia OIT, pues poco después de la proclamación de la República, el 25 de abril de 1931, la Ejecutiva de UGT daba cuenta de una decisión del director de Trabajo (de la Oficina de Trabajo de la OIT) donde pide que:

... se designe un delegado efectivo y tres asesores técnicos, uno de ellos mujer, para asistir a la próxima Conferencia Internacional del Trabajo en representación de la $\mathrm{UGT}^{23}$.

Ante esa circunstancia ineludible la elegida fue «Regina García, que conoce el francés y puede representar dignamente a la Unión». El delegado nombrado era Wenceslao Carrillo, que sustituía a Largo Caballero y los otros dos asesores eran Cordero y Peña.

Regina García hasta entonces era una desconocida en la UGT, pues se había afiliado al PSOE sólo un año antes, en 1930. Pero en los foros internacionales el hecho de tener una formación intelectual - era escritora y hablaba francés - , aunque no fuera universitaria, eran valores añadidos. Su carrera política fue muy rápida; en 1931 ya figuraba en una relación de candidatos a concejales de la Agrupación Socialista Madrileña ${ }^{24}$.

Regina García es un personaje bastante enigmático, pues apenas aparecen datos personales, si exceptuamos los que aporta la sentencia condenatoria por «auxilio a la rebelión», dictada por el Tribunal Nacional de Responsabilidades Políticas franquista en 1940. Esta señala su trayectoria política desde los inicios:

Originaria de La Coruña, donde nació en 1900, casada, escritora, afiliada a UGT y PSOE desde 1930; delegada de trabajo en el Bureau Internacional de Ginebra, di-

23 Acta de la reunión de la Comisión Ejecutiva de la UGT, 25 de abril de 1931: 39, FPI, AARD, 255-2: «Enrique Santiago propone a Carrillo como delegado por ser este quien sustituye a Caballero en la Unión. Como asesores técnicos propone a Peña, secretario de la Federación de ingenieros, Anastasio de Gracia y Regina García, que conoce el francés y puede representar dignamente a la Unión. Se acuerda en primer término que el delegado sea Carrillo. Tratóse luego de los asesores y Carrillo dice que le parece bien la propuesta de Peña y Regina, pero estima que debería ser Cordero y no De Gracia, por desempeñar el primero el cargo de presidente de la Unión. Intervienen otros compañeros y se acuerda que los asesores sean Cordero, Peña y Regina García».

24 Documento del Archivo Ángel Galarza, CDMH, Archivo Político-Social, 303. También aparece Regina García en ese archivo, como secretaria del Consejo Superior del Patronato de Protección a la Mujer en octubre de 1931. 
rectora de la Voz del Combatiente y jefe de prensa del Comisariado General de Guerra $^{25}$.

Además tenemos su controvertido testimonio autobiográfico titulado Yo he sido marxista. El cómo y el porqué de una conversión ${ }^{26}$, escrito con carácter exculpatorio en Madrid y publicado el año 1946. El capítulo VII lo dedica a su participación en la OIT e introduce, junto al relato de su trabajo en este organismo, comentarios favorables al papel social del franquismo.

Isabel Oyarzábal, nacida en Málaga en 1883, había conocido la cultura inglesa a través de su madre y de los viajes que realizó a Inglaterra y Escocia. En Inglaterra también contactó con algunas sufragistas que le hicieron cambiar de mentalidad, según ella misma reconocía en su autobiografía ${ }^{27}$; estos conocimientos le permitirían moverse con facilidad en la arena internacional durante el periodo republicano aunque, como señala Matilde Eiroa, no podía aportar conocimientos profundos, dado que carecía de una formación universitaria y era una autodidacta, como la mayoría de las mujeres de su tiempo.

Ambas mujeres representarán al PSOE y la UGT en la OIT y la SDN con posturas distintas sobre las relaciones de género en el ámbito público. Mientras que Isabel de Palencia ${ }^{28}$ pertenecía a varias organizaciones feministas y estaba de acuerdo con las partidarias de la equiparación legal de mujeres y hombres, Regina García seguía la línea proteccionista marcada por la FSI y la UGT.

La XV conferencia de la OIT auspició una reunión femenina de la FSI en Lausana para tratar las cuestiones sindicales que afectaban a las mujeres. Regina García, como representante del sindicato español, recordaba haber intervenido en aquel encuentro: «Hablé de nuestra joven República y del programa que nos proponíamos desarrollar, logrando un éxito oratorio». Además, hizo un resumen de la reunión para el Boletín de la UGT de España, titulado «La Conferencia Internacional del Trabajo de la Federación Sindical Internacional. Reunión femenina» ${ }^{29}$. Decía allí que una de las cuestiones más debatidas fueron las dificultades que observaban las «camaradas» de la FSI para interesar a las trabajadoras de sus países en la acción sindical y los medios para salvarlas, algo ya debatido en anteriores reuniones. Al enumerar esos

25 Sentencia condenatoria del Consejo de Guerra del 1/12/1940, CDMH, Archivo del Tribunal Nacional de Responsabilidades Políticas, sala 1. Figura que fue condenada por auxilio a la rebelión a 12 años y un día de prisión; en 1944 se le conmuta a 6 años.

26 GARCÍA, 1952.

27 EIROA, 2014: 186-190.

28 Isabel de Palencia era su nombre de casada, que ella usaba en los foros públicos como la OIT y la SDN.

29 Regina García, «La Conferencia Internacional del Trabajo de la Federación Sindical Internacional. Reunión femenina», Boletín de la Unión de Trabajadores de España, 3/7/1931, Madrid: 171-172, FPI. 
problemas muestra con claridad cómo las propias sindicalistas defendían el modelo de división del trabajo entre géneros más tradicional, el breadwinner family, y asumían los estereotipos que se derivaban del ideal femenino de la domesticidad. Sin embargo, la postura de Regina es ambigua, se adhiere al modelo tradicional, como era común entonces, pero critica algunos aspectos. Según ella, las dificultades para la acción sindical femenina señaladas en aquella reunión eran, en primer lugar, las que planteaba la maternidad. La delegada española comentaba que ese problema «podría subsanarse si se reconociera a la maternidad su función social» y, mientras tanto, proponía que se celebraran reuniones en «las horas que menos pudieran interrumpir los deberes del hogar de las mujeres obreras $\rangle^{30}$.

Las sindicalistas de la FSI — según la autora—, estimaron también las dificultades «de orden fisiológico» que afectaban a las mujeres, por «sus frecuentes indisposiciones y la inestabilidad de su estado de salud» que las hacían débiles por naturaleza. Regina rebatía esos argumentos diciendo que «lo mismo ocurre con gran número de obreros» que no gozan de buena salud y que un salario digno mejoraría la salud de la obrera. También se oponía al argumento del «sentimentalismo femenino» como motivo para la escasa sindicación de las mujeres, considerando que los sentimientos podían aprovecharse para mostrarles las ventajas de la afiliación sindical para ellas y para sus hijos. Concluye el resumen de la reunión señalando los medios por los que se trataba de interesar a las trabajadoras en la acción sindical, en opinión de las mujeres de la FSI. La propaganda escrita era uno de los mejores medios con los que se contaba entonces, aunque Regina dudaba de su eficacia dada «la escasa afición por la lectura de las mujeres españolas», algo que se relacionaba con su alto grado de analfabetismo. A continuación señalaba la propuesta de celebración de un congreso internacional femenino en Ginebra para el mes de febrero de 1932, un proyecto que varias veces tuvo que abandonarse por no tener suficiente número de mujeres afiliadas a organizaciones sindicales, como había ocurrido en España.

Regina García formaba parte de tres comisiones del Buró Internacional del trabajo, BIT Según su relato de aquellas reuniones, fue designada para participar en:

La del trabajo nocturno de la mujer, en la que figuraba como único vocal español; la del trabajo de los menores, en la que me acompañaba Cordero, y la del trabajo en las minas de carbón, con Wenceslao Carrillo ${ }^{31}$.

30 Regina García, «La Conferencia Internacional del Trabajo de la Federación Sindical Internacional. Reunión femenina», Boletín de la Unión de Trabajadores de España, 3/7/1931, Madrid: 172, FPI.

31 GARCÍA, 1952: 78. 
Medio año antes - las reuniones tenían que prepararse con mucha antelación-, la FSI comunicaba a la Ejecutiva de la UGT la propuesta del gobierno británico de revisión del convenio de la OIT sobre el trabajo nocturno para que se pronunciase. Dicha proposición del gobierno inglés pedía que:

Se levante la prohibición del trabajo de noche para las mujeres que ocupan un puesto de dirección o de vigilancia. La Conferencia Sindical inglesa se ha manifestado en contra de este deseo del Gobierno y la Internacional espera que las centrales nacionales se pronunciarán en el mismo sentido ${ }^{32}$.

Igual que había ocurrido con sus homólogos masculinos, Regina García, como miembro de la delegación obrera, se mostraba totalmente en contra de esa revisión, siguiendo la línea marcada por anteriores debates sobre el tema, que veían un avance en las normas limitadoras del trabajo femenino. Publicó su opinión en el artículo titulado «El trabajo nocturno de la mujer» en el Boletín de UGT de agosto de 1931; allí la socialista española reseñaba las discusiones de la sesión de la XV Conferencia Internacional del Trabajo en torno a ese controvertido asunto. Según ella, «la prohibición de estos trabajos respecto a mujeres y menores supone un baluarte ganado para la consecución del triunfo $\mathrm{y}$, por lo tanto, resultaba absurdo transigir por una revisión ${ }^{33}$. Esta no se produjo y el convenio quedó finalmente ratificado en su versión original.

En esta misma línea escribía en El Socialista, del 11 de junio de 1931, un artículo titulado «Feministas y obreras»34, que tiene el interés de exponer sus críticas al planteamiento feminista de la igualdad en el trabajo, defendido en aquella Conferencia Internacional del Trabajo por las mujeres de la Asociación Femenina Internacional Open Door. Este grupo feminista defendía las mismas posturas de igualdad de derechos laborales entre mujeres y hombres que los grupos americanos ya citados - la Inter American Commission of Women y la Equal Right International-, y había salido a la luz el año antes a raíz del debate de la postura del gobierno inglés respecto al trabajo nocturno de las mujeres. Sobre su posición, Regina comentaba lo siguiente:

32 «La FSI informa de que el Gobierno inglés quiere que se levante la prohibición del trabajo de noche para las mujeres que ocupan un puesto de dirección o de vigilancia. (...). Pide a Caballero que apoye sus deseos. La ejecutiva faculta al secretario para que se pronuncie como estime más a favor de los intereses de los trabajadores», Acta de la reunión de Comisión Ejecutiva de la UGT, 18 de diciembre de 1930: 139, FPI, AARD, 255-2.

33 Regina García, «La Conferencia Internacional del Trabajo. El trabajo nocturno de la mujer», Boletín de la Unión de Trabajadores de España. 3/8/1931, Madrid: 206-207, FPI.

34 Regina García, «Feministas y obreras. Alrededor de la Conferencia Internacional del Trabajo» El Socialista, 11/6/ 1931, Madrid: 4, FPI. 
En relación con este asunto hay una circular del grupo belga de la Puerta Abierta pronunciándose en sentido favorable a la propuesta del gobierno inglés que desea se amplíe para todos los trabajos que realizan las mujeres ${ }^{35}$.

El artículo de Regina resumía la posición del lobby feminista que se decía contrario a la teoría de la subordinación de la mujer al hombre ${ }^{36}$, para luego criticarla:

Enfocan la cuestión desde un punto de vista de derecho y declaran que la mujer aspira a todo lo que hoy disfruta el hombre; exigen que las leyes que reglamentan el trabajo se basen en la naturaleza del trabajo mismo y no en una razón de sexo, y estiman que las limitaciones impuestas por esta razón son otras tantas trabas a los derechos de la mujer, entre los cuales está, naturalmente, el de ganarse la vida con su trabajo ${ }^{37}$.

Su crítica a las partidarias de las posturas igualitarias repite algunos tópicos antifeministas, considerando a sus defensoras «mujeres ociosas» fuera de la realidad de las trabajadoras, dedicadas a «redactar folletos», mientras que «se olvidan un poco de defender los sagrados fueros del sexo, de ese sexo del que quieren prescindir las exaltadas feministas». Una vez más defiende la necesidad de leyes protectoras y no igualitarias para la mujer, que tengan en cuenta, dice «las servidumbres que le impone la augusta función maternal» ${ }^{38}$.

El trabajo en las minas de carbón fue otro de los temas que suscitó mayores discusiones, según figura en las memorias de Regina:

En el grupo obrero habíamos acordado mantener tres ponencias: prohibir el trabajo de la mujer encinta (...); reducir en una hora la jornada de trabajo de los mineros... y contar la duración de la jornada desde la llegada a la bocamina y no desde el tajo, como solía hacerse entonces ${ }^{39}$.

Según su relato, los patronos estuvieron de acuerdo en las medidas relacionadas con la prohibición del trabajo en las minas de las mujeres embarazadas, pero no aprobaban la reducción de la jornada por su coste económico; finalmente se aceptó la propuesta del grupo gubernamental de rebajar la jornada sólo en un cuarto de hora, comenzando desde la llegada a la bocamina.

35 Regina García, «Feministas y obreras. Alrededor de la Conferencia Internacional del Trabajo», El Socialista, 11/6/1931, Madrid: 4. Para el grupo «Open Door» de Bélgica, ver JACQUES, 7 (Bruselas, 2009), https://www.cairn.info/revue-courrier-hebdomadaire-du-crisp2009-7-page-5-54.htm.e.

36 JACQUES, 2006: 267-277.

37 Regina García, «Feministas y obreras. Alrededor de la Conferencia Internacional del Trabajo», El Socialista, 11/6/1931, Madrid: 4.

38 Regina García, «Feministas y obreras. Alrededor de la Conferencia Internacional del Trabajo», El Socialista, 11/6/1931, Madrid: 4.

39 GARCÍA, 1952: 79. 
Regina García, como delegada del grupo obrero, continuó durante la República su labor y fue miembro del Comité de Expertos en el Trabajo femenino, compuesto únicamente por tres mujeres. Años más tarde, viviendo ya en la España franquista rememoraba con orgullo sus aportaciones: «en ese cargo fui reelegida dos veces por períodos de tres años, con la obligación de enviar un informe mensual a Ginebra ${ }^{40}$. Ello a pesar de que ya hubiera renegado del socialismo y a continuación escribiera el siguiente comentario a favor del régimen de Franco:

... quien (sic) diría entonces a los obreros españoles que mayores avances en materia de organización del trabajo habría de darles sin presiones de los organismos internacionales, un Estado sindicalista, no federado, antimarxista y tradicionalista ${ }^{41}$.

Un mayor protagonismo en la Organización Internacional del Trabajo lo tuvo Isabel de Palencia. Su destacado papel en la SDN y la OIT va siendo más conocido gracias a las investigaciones de Matilde Eiroa, Giuliana Di Febo y Olga Paz ${ }^{42}$. Isabel de Palencia estuvo presente allí en mayo y junio de 1931. Como miembro de la comisión sobre el trabajo de los menores en aque1la Conferencia, Isabel realizó propuestas sobre la reducción del trabajo infantil, nombrando especialmente el caso de la infancia en el medio rural español. Hizo un discurso sobre la explotación de los niños que trabajaban de monaguillos en las iglesias que no fue siquiera discutido, por lo que en sus memorias afirmaba que se sintió incomprendida ${ }^{43}$.

$\mathrm{Su}$ alta cualificación como inspectora de trabajo por oposición le permitió formar parte del grupo de «expertos» en cuestiones laborales. En 1932 se le propone formar parte del Comité de Expertos sobre el Trabajo Femenino, a lo cual accede gustosa. En su calidad de integrante de ese comité, se reuniría para estudiar la problemática de las trabajadoras de la industria ${ }^{44}$, aunque también se ocupó del candente debate sobre la nacionalidad de la mujer casada.

Matilde Eiroa señalaba además otras ocasiones en las que Isabel de Palencia participó en ese organismo como consejero técnico; primero formando parte de la delegación española, como representante gubernamental en la XVII Conferencia Internacional del Trabajo en 1933 y en la Conferencia In-

40 GARCÍA, 1952: 83.

41 GARCÍA, 1952: 81. Regina también criticaba que los italianos estaban excluidos del grupo obrero de la FSI a pesar de que «su nación era una de las primeras en ratificar los convenios sobre mejora en las condiciones de trabajo lo que la ponía entre los pueblos más justos en legislación obrera».

42 EIROA, 2014. DI FEBO, 2009: 129-146. PAZ, 2010.

43 PAZ, 2010: 475-476 (anexo documental).

44 EIROA, 2014: 186-190. 
ternacional de Colocación que se celebraba en junio de ese mismo año. Giuliana Di Febo apuntaba una cuestión relevante para entender las posturas que allí defendía la socialista, cuando escribe que en las sesiones de octubre de 1933 Isabel «rindió homenaje a la Alianza Internacional de Mujeres Sufragistas», que antes había apoyado castigar el abandono familiar ${ }^{45}$. Este hecho indica su cercanía a las posturas del lobby feminista internacional, en oposición a las críticas de Regina García hacia la equiparación total de derechos entre mujeres y hombres.

En 1935 se negó a ir como representante del gobierno radical-cedista; sin embargo, acudió como delegada obrera en septiembre de 1936, ya en plena guerra civil y en la sesión del 3 octubre de 1936 participó en la discusión sobre la protección de la infancia rural. En esa reaparición, escribía Isabel en sus memorias ${ }^{46}$, nota la frialdad hacia la República de la mayoría de los representantes excepto los de México y la URSS.

Intervino también en la XXIII Conferencia Internacional del Trabajo celebrada en 1937. Olga Paz resume así las intervenciones de Isabel en aquellos momentos de guerra, el 11 de mayo de 1937:

Se centran en destacar el papel pionero de la República en la defensa de la legislación laboral internacional, en la defensa de las 40 horas semanales de jornada y en los derechos laborales de las trabajadoras, especialmente madres y en la legislación infantil ${ }^{47}$.

Finalmente tuvo una intervención en la sesión de la Comisión consultiva de expertos en materia de esclavitud el 31 de marzo de 1938; allí se debatió un informe del gobierno británico sobre la situación de diversas poblaciones bajo su protectorado. Isabel habló sobre la cuestión de las esclavas sexuales vendidas para ejercer la prostitución en lugares como Hong Kong, algo que consideraba de gran importancia, según reflejan las actas de la $\mathrm{SDN}^{48}$. Un comunicado con fecha de 5 de octubre de 1939 la considera «virtualmente dimisionaria» de la comisión de expertos de la Sociedad de Naciones ${ }^{49}$, tras la derrota del gobierno republicano al que siempre apoyó.

No tenemos noticias de que hubieran intervenido las representantes españolas en la OIT en torno al problema del estatuto jurídico y la nacionalidad de las mujeres, que también fue una cuestión muy discutida en la Federación

45 DI FEBO, 2009: 142, añade que en esa fecha Isabel intervino sobre la trata de mujeres y el tráfico de niños.

46 DI FEBO, 2009: 143-144.

47 PAZ, 2010: 269.

48 PAZ, 2010, 288. Se basa en el Acta del cuarto periodo de sesiones de la Comisión Consultiva de Expertos en materia de esclavitud, el 31 de marzo de 1938: 1-7.

49 PAZ, 210: 483. 
Sindical Internacional a lo largo de los años treinta. El buró de la FSI había requerido a los sindicatos nacionales su opinión acerca del trabajo de la mujer casada y su estatuto legal, pero la propia posición oficial de la Federación Internacional era confusa; por un lado se mostraba a favor del principio de «a trabajo igual, salario igual» en relación con las mujeres trabajadoras, lamentando que no se cumpliera, pues perjudicaba a hombres y mujeres, mientras que por otra parte consideraba a las mujeres seres débiles cuando pedía que fueran protegidas por leyes especiales y recomendaba que:

En principio los sindicatos no hagan campaña contra el trabajo de las mujeres casadas, lo cual equivaldría a establecer una exclusiva para una parte del proletariado, salvo los casos de crisis intensa de trabajo, debiendo en estos casos ser eliminados los individuos más débiles, lo cual no quiere decir que sean solo las mujeres. No admiten tampoco el principio de que la mujer casada se encuentra económicamente en una situación de privilegio ${ }^{50}$.

Además, su posición favorable a la actividad laboral tras el matrimonio tenía reparos, pues podía modificarse en tiempos de crisis económica.

Profundizando en el tema del estatuto legal de la mujer casada, la FSI redactó en 1935 un Memorandum con el fin de que fuera presentado en la Asamblea de la Sociedad de Naciones de septiembre de aquel año, en nombre del Comité Sindical Internacional de Trabajadoras. En sus planteamientos seguían las reticencias a la equiparación legal de mujeres y hombres, pues consideraban que debían mantenerse algunas distinciones legales basadas en el sexo:

El Comité está, en general, de acuerdo con el principio de igualdad consagrado en la convención de Montevideo; sin embargo, el Comité advierte contra toda decisión precipitada en relación con esta convención. Se presupone que la propuesta de suprimir las distinciones legales basadas en el sexo no debe poner en peligro la legislación protectora de las trabajadoras que ya existe en algunos países (...). Desde siempre, el Comité Sindical Internacional de las Trabajadoras ha considerado que a) la mujer casada debe tener el derecho de elegir libremente conservar su nacionalidad o adoptar la de su esposo... c) es necesario que todas las mujeres sean informadas de estos derechos para que sepan que cualquier cambio en el régimen legal del matrimonio debe contar con su consentimiento ${ }^{51}$.

Como vemos, la FSI se mostraba de acuerdo con las resoluciones adoptadas dos años antes por la Conferencia Internacional Americana, referentes a la nacionalidad de la mujer, que en su artículo 6 establecía que «Ni el matri-

50 Acta de la reunión de la Comisión Ejecutiva de la UGT, 25 de abril de 1931: 39, FPI, AARD, 255-2.

51 Traducción propia del Memorandum de L'Oeuvre de la FSI (1933-1935), 1936, IIHS, IFTU, 191-192. 
monio ni su disolución afectan a la nacionalidad de los cónyuges o de sus hijos $\rangle^{52}$. Y sin embargo no renunciaba a sus principios proteccionistas.

No contamos con información acerca de la opinión de la UGT y las socialistas españolas sobre esta importante cuestión, aunque parece claro que la postura con la que se alineaba la representante sindical, Regina García, era la misma que planteaba la FSI en este Memorandum.

En el debate sobre los principios rectores de la legislación para las mujeres quedaba claro el triunfo de los partidarios de una legislación proteccionista, frente a los defensores de la equiparación de derechos entre mujeres y hombres.

\section{LA FSI Y LAS TRABAJADORAS ANTE EL AVANCE DEL FASCISMO}

Desde los años veinte, los sindicatos y la Federación Sindical Internacional estaban preocupados por el ascenso del fascismo en Europa y en concreto por el retroceso en los derechos laborales de las mujeres en los países totalitarios, un proceso que iba unido a «los esfuerzos en los medios pro-fascistas de eliminarlas de la vida industrial ${ }^{53}$. Para intentar contrarrestar el avance del fascismo, en 1933 el Congreso Sindical Internacional, reunido primero en Zúrich y luego en Bruselas, había puesto en marcha el boicot económico y "moral» a la Alemania hitleriana; el balance de ese boicot que aparece en L'Oeuvre de la FSI (1933-1935)54, era moderadamente optimista, incluso para el caso español, pues entonces las candidaturas del Frente Popular acababan de ganar las elecciones generales. Se destacaba la solidaridad sindical mostrada tras la llamada de socorro para ayudar a las víctimas de la represión después de «el heroico levantamiento de las masas populares españolas en octubre de 1934 y la represión sanguinaria que abatió al movimiento proletario» ${ }^{55}$. Las dos instituciones internacionales, la FSI y la Internacional socialista, habían enviado una delegación conjunta a España para presionar al gobierno de Lerroux, cuando numerosos socialistas españoles fueron encarcelados.

Matilde de la Torre, diputada socialista por Oviedo desde 1933, tuvo entonces una importante proyección nacional e internacional en aquellos momentos. Maestra, escritora y periodista de profesión, tras la sublevación de Asturias intervino sumándose a la campaña de solidaridad internacional a favor del indulto al presidente de la Diputación de Oviedo, Ramón González Peña, condenado a muerte y por la libertad de Largo Caballero. El 15 de febrero de 1935, Matilde hizo una visita a Alejandro Lerroux en la que solicitó

52 Convención sobre la nacionalidad de la mujer de Montevideo (26 de diciembre de 1933), http://www.cndh.org.mx/sites/all/doc/programas/mujer/7_Indicadores/ins/C.pdf.

${ }^{53}$ L'Oeuvre de la FSI (1933-1935), IIHS, IFTU, 89.

${ }^{54}$ L'Oeuvre de la FSI (1933-1935), IIHS, IFTU, 131-140.

55 L'Oeuvre de la FSI (1933-1935), IIHS, IFTU, 140 (traducción propia). 
el indulto para los represaliados de Asturias ${ }^{56}$, sumándose a la presión de los sindicatos socialistas. Sin embargo su papel más destacado a nivel internacional lo tuvo durante la Guerra Civil, cuando intervino a favor de la causa republicana en varios países. Tenemos constancia de su exitoso discurso en el Congreso de las Femmes Socialistes Belges y en una gran manifestación en honor a España y en defensa de Checoeslovaquia ${ }^{57}$.

Además del problema del fascismo, la FSI advertía de otra amenaza que se cernía sobre los derechos laborales de las trabajadoras. Se trataba de las posiciones adoptadas por los sindicatos cristianos que «pretenden que se elimine del trabajo a la mujer casada y a la madre de familia para que dejen su puesto a los obreros parados $\rangle^{58}$, actuando en este terreno en la misma línea que los gobiernos fascistas. Con objeto de «impedir esas maniobras» del sindicalismo católico, en agosto de 1935 la Federación Sindical Internacional preparaba «una reunión del Comité Internacional de las mujeres obreras pedida por dos compañeras que forman parte del Comité de la FSI». Para ello consultaba a la Ejecutiva de UGT su parecer; como era ya habitual, el sindicato español estuvo de acuerdo con la iniciativa de la FSI, pero declinó la posibilidad de enviar a alguna representante española a aquella asamblea. La reunión tuvo lugar en París y gracias a la oposición del Comité Sindical Internacional de Trabajadoras no prosperó esa propuesta limitadora de los derechos laborales de las mujeres casadas. Este Comité Internacional de trabajadoras se había reestructurado a raíz de la desaparición de la representación de Alemania como consecuencia del triunfo del nazismo. En efecto, el año 1935 la delegada alemana había sido sustituida por la checoslovaca, quien pasaba a ser miembro titular del Comité. La novedad fue la participación de Claudina García como miembro suplente del Comité Sindical Internacional representando a España ${ }^{59}$.

56 VILCHES, 2015, señala que se afilió al PSOE en mayo de 1931, a instancias de Fernando de los Ríos. Firme defensora de los derechos de las mujeres, incluido el voto, fue reelegida diputada en febrero de 1936.

57 Correspondencia entre Ramón Lamoneda e Isabelle Blume, 28 abril de 1938 y 28 mayo del 1938, FPI, AH, 73.9. La intervención de Matilde de la Torre fue muy aplaudida. Un mes después Isabelle Blume la felicitaba por su discurso sobre la situación internacional que resultó «tan conmovedor como instructivo».

58 Acta de la Comisión Ejecutiva del 8 de agosto de 1935, FPI, AARD, 256-2 continúa así: «Consulta la FSI si se está conforme con que se celebre esta reunión, y en caso afirmativo, propone que sea el 10 de septiembre, a las diez de la mañana, en París. Y si se considera posible agregar a los dos puntos mencionados algún otro. La Comisión ejecutiva acuerda manifestar su conformidad con que se reúna el Comité, de que se trata, si bien advirtiendo que la Unión General de Trabajadores no puede enviar representación». También se recoge esta misma cuestión en L'Oeuvre de la FSI (1933-1935), IIHS, IFTU, 92.

59 L'Oeuvre de la FSI (1933-1935), IIHS, IFTU, 92-94, capítulo dedicado a «Cuestiones femeninas». 
Es un síntoma de la presencia del feminismo en el Comité Sindical Internacional de Trabajadoras que el Memorandum de 1936 dedicara un epígrafe a la «emancipación civil y política» de las mujeres. En él se presentaba un panorama de su situación en el mundo occidental (no se hablaba de la situación a nivel mundial) bastante optimista por los derechos conseguidos, minimizando los problemas causados por el avance del fascismo. Se destacaban los avances en el camino de la igualdad:

El número de mujeres que militan para conseguir su emancipación política y civil aumenta sin cesar y sus esfuerzos para conquistar más igualdad encuentran cada vez más apoyo en la opinión pública del mundo entero, tanto en los hombres como en las mujeres. Desde la guerra se puede constatar con satisfacción que en el campo de los derechos políticos, civiles, económicos y sociales de la mujer se han realizado progresos considerables, como ha ocurrido internacionalmente en otras áreas de la vida política, económica y social. En algunos países las mujeres han obtenido la igualdad política total; en otros, incluso, la igualdad total en materia de derechos civiles. No se puede negar, sin embargo que, en la mayoría de países, incluso los más avanzados en el aspecto político y social, esta evolución hacia más igualdad entre los sexos no ha seguido el ritmo que cabía esperar inmediatamente después de la guerra. Al contrario, en algunos países, la diferencia de trato, la discriminación entre los derechos de la mujer y los del hombre son tales que suscitan la indignación de la opinión pública, y sobre todo de las mujeres, cuando se dirige la atención sobre este estado de $\cos ^{6}{ }^{60}$.

Sólo en este último párrafo se aludía al preocupante retroceso en los derechos de las trabajadoras que estaban viviendo los países con regímenes totalitarios, como Italia y Alemania, que condicionaría la situación venidera. Ese optimismo quedó truncado con el avance del fascismo por España y Europa.

En este contexto, Claudina García aparecerá por vez primera en el Comité Sindical Internacional de Trabajadoras como delegada por España en la Conferencia Internacional de Trabajadoras que había convocado el buró de la FSI. Esta se celebró en Londres, el 7 de julio de 1936, un día antes de que iniciara sus trabajos el congreso de la Federación Internacional de las Trade Unions (8 al 11 de julio de 1936).

Claudina había sido anteriormente propuesta por la UGT - junto a otras sindicalistas - para formar parte de un «Comité de estudio sobre cuestiones relacionadas con el trabajo femenino», que había sido votado por la Conferencia Internacional del Trabajo de 1932, según lo explicaba la FSI en una de sus comunicaciones a la Ejecutiva de UGT fechada en marzo de $1932^{61}$. En la

${ }^{60}$ L'Oeuvre de la FSI (1933-1935), IIHS, IFTU, 192.

${ }^{61}$ Acta de la Comisión Ejecutiva, 16 de marzo de 1932: 40, FPI, AARD, 256-1, «Da cuenta de que habiendo sido votada por la Conferencia Internacional del Trabajo una resolución tendente a crear un Comité de correspondencia encargado del estudio de cuestiones rela- 
lista figuraban cuatro mujeres: «Regina García, Ángeles Vázquez, Victoriana Herrero y Claudia García» y no es casual el hecho de que dos de las sindicalistas que pudieron tener un papel destacado en la FSI fueran antiguos miembros de la Agrupación Socialista de Mujeres de Madrid, la más preocupada por la «cuestión femenina». Allí se encontraban con militantes tan activas como Claudina García, a la que se sumaba la desconocida Victoriana Herre$\mathrm{ro}^{62}$. Sin embargo, no parece que dicho Comité llegará a contar con presencia española hasta la Conferencia de 1936, dadas las reticencias de la Ejecutiva a enviar a representantes femeninas a la FSI.

Claudina García tenía una amplia trayectoria como sindicalista y defensora de los derechos civiles y laborales de las mujeres. Además era la secretaria general de la Federación Nacional de la Industria del Vestido y el Tocado de UGT, por lo que pertenecía al Comité Nacional de la UGT desde 1932; de ahí que fuera lógica su designación como representante española en la Conferencia Internacional de las Trabajadoras ${ }^{63}$, aunque no hay información sobre su intervención. En enero de 1938 Claudina aparecía formando parte de la nueva ejecutiva del PSOE en el puesto de vocal, siendo la única mujer que ostentaba ese cargo de 1937 a $1939^{64}$.

Los temas propuestos a la discusión en la Conferencia de Trabajadoras de Londres fueron los que se estaban discutiendo en otros foros internacionales:

cionadas con el trabajo femenino y (...) pide que se dé el mayor apoyo posible de candidatos por cada país para formar parte de ese Comité, rogándonos demos los nombres de las compañeras que estimemos que están en condiciones de poder realizar esta labor. Se envía una lista con los nombres de las siguientes compañeras: Regina García, Ángeles Vázquez, Victoriana Herrero y Claudia García».

62 Victoriana Herrero Barroso, Logroño 23/03/1893 - Madrid 01/10/1962, miembro de la Sociedad de Profesiones y Oficios Varios y posteriormente de la Sociedad de Obreros de la Aguja de la UGT. Afiliada a la Agrupación Femenina Socialista de Madrid desde 1925. Fue vocal del Comité del grupo socialista madrileño en los años de la dictadura de Primo de Rivera, Diccionario Biográfico del Socialismo español, fpabloiglesias.es/archivo-y-biblioteca/ diccionariobiografico/busquedabiografias.

63 Diccionario Biográfico del Socialismo Español, http://www.fpabloiglesias.es/archivoy-biblioteca/diccionario-biografico: Claudina García participó en la fundación de la Asociación de Obreras de Ropa Blanca y similares de Madrid y sus limítrofes, creada el 29 de enero de 1928.

${ }^{64}$ Correspondencia de Ramón Lamoneda con el Secretariado Femenino del PSOE, 1938, Archivo FPI. En el exilio Claudina fue una destacada militante de la Unión de Mujeres Españolas escribiendo artículos en su revista sobre los derechos de las mujeres, ver DOMÍNGUEZ, 2009. Claudina García, tras permanecer encarcelada hasta 1941, había salido de España rumbo a Francia y luego a México. Mantiene correspondencia con Isabelle Blume, ver Claudina Garcia (secret. femenina du P.S.O.E.) e I. Blume: Creation d'un Secretariat Feminin International et renseignements sur la situation interieure de l'Espagne sous Franco, Paris, 21/6/1947 a 5/7/1947, Inventario de los Fondos del Archivo de I. Blume, http://www.iev.be/getattachment/ 3485cc30-fc0a-40d7-81c3-7a497c3c1fd4/PS_test-(1).aspx. 
El problema de las 40 horas para las mujeres; el trabajo de las mujeres en la industria; la libertad de trabajo para las mujeres en relación con ciertas medidas restrictivas tomadas por algunos países y el problema del estatuto jurídico y la nacionalidad de las mujeres ${ }^{65}$.

Pocos días después de la Conferencia, el golpe militar franquista y la consecuente guerra civil hicieron cambiar las prioridades en el discurso y en la actividad política y sindical de mujeres y hombres. Las discusiones en torno al trabajo remunerado femenino dejan de tener importancia en aquellas circunstancias en las que la República está en peligro, aunque es en plena guerra, en 1937, cuando el Partido Socialista crea por fin un Secretariado Nacional Femenino ${ }^{66}$; algunas de sus dirigentes como Claudina García y Matilde de la Torre fueron muy activas en la arena política internacional. Este escenario cobra cada vez mayor relevancia en el transcurso de la guerra, por lo que las militantes socialistas centrarán sus esfuerzos en conseguir la solidaridad material de partidos y sindicatos a favor de la República española, usando las redes de la Federación Sindical Internacional y la Internacional Socialista ${ }^{67}$.

En este terreno hay que resaltar la intensa labor propagandista de otra de las socialistas aquí citadas, Isabel de Palencia, quien por su destacado papel internacional fue comisionada por el PSOE y la UGT en Gran Bretaña junto a Luis Jiménez de Asúa. Ambos asistieron al Congreso del Partido Laborista escocés en Edimburgo (7-10 octubre de 1936) con el fin de explicar la situación de la República en guerra y tratar de convencer al laborismo inglés y al ministro Neville Chamberlain para apoyar activamente al gobierno republicano contra el pacto de no intervención. Sus discursos, aunque no lograran sus objetivos, fueron muy bien acogidos y se recogieron en el panfleto titulado «The Agony of Spain» publicado por el Partido Laborista ${ }^{68}$.

Tras la derrota republicana la mayoría de ellas: Isabel de Palencia, Matilde de la Torre, entre otras muchas socialistas y republicanas, se vieron obligadas al exilio o situaciones más duras como la cárcel que sufrió Claudina García. De estas mujeres sólo se libró del exilio Regina García, quien tras permanecer cuatro años en la cárcel y abjurar de sus ideas marxistas, vio sobreseída su causa y se convirtió en una propagandista del nacional-sindicalismo, por lo que pudo permanecer en España el resto de su vida.

65 L'Oeuvre de la FSI (1933-1935), IIHS, IFTU, 91.

66 «La Comisión Directora del Secretariado Femenino contaba con Matilde Huici, Matilde Cantos, Claudina García y Julia Álvarez Resano, quien actuaba de secretaria», CAPEL, 7 (Madrid, 2008): 120.

67 Sobre este tema ver DOMÍNGUEZ, 38 (Roma, 2016): 58-77.

68 The Agony of Spain». Speeches of Señor de Asua and Señora de Palencia at Edinburgh Conference, Archives of the Trade Union Congress, Spanish Civil War, Warwick Digital Collection, http://contentdm.warwick.ac.uk/cdm/ref/collection/scw/id/944/rec/4. 
El régimen franquista abandonó la OIT y todos sus compromisos legales y se opuso firmemente a la igualdad legal entre mujeres y hombres; sin embargo, es paradójico que — como afirmaba Regina García—, algunas medidas de carácter proteccionista como la supresión del trabajo nocturno de las mujeres, «por lo que tanto luchamos en la comisión (de la OIT) en la que yo figuraba» ${ }^{69}$, eran del agrado del franquismo, firme defensor de la asimetría de género y se mantuvieron en España desde 1938 en el Fuero del Trabajo.

Habría que esperar al final de la II Guerra Mundial, con la creación de la Carta de Derechos de la ONU (28 octubre 1945), para que se consiguiera la equiparación total de derechos entre mujeres y hombres. España quedaría al margen de ese proceso.

\section{CONCLUSIONES}

El papel de las socialistas españolas en los organismos sindicales internacionales fue reducido por las limitaciones que imponía el modelo de género de la domesticidad y por su alejamiento de los núcleos tradicionales del poder en el sindicato UGT, poco interesado en enviar a eso foros una representación femenina. Sin embargo, las asociaciones internacionales de mujeres habían tenido una importante presencia en la Sociedad de Naciones y la OIT desde 1919, convirtiéndose en actores transnacionales durante el período de entreguerras en defensa de la igualdad legal entre mujeres y hombres.

En el caso de España, la ausencia de representación sindical internacional femenina fue habitual hasta 1931. La presencia de las mujeres en la escena pública, en la SDN y la OIT, se produjo durante el período republicano, de acuerdo con el proceso de incorporación de las mujeres a la actividad política y sindical que se estaba desarrollando en aquellos años en España. En esos foros destacó la presencia de Regina García e Isabel de Palencia, que en los debates defendían posturas contrapuestas acerca del papel de las mujeres en el ámbito laboral. Regina García, como defensora de la postura oficial de UGT, era partidaria de un trato específico hacia las mujeres en el mercado de trabajo, considerándolas dignas de protección al igual que la infancia; sin embargo, Isabel de Palencia, cercana al feminismo, abogaba por la igualdad de derechos entre mujeres y hombres.

Las intervenciones de las representantes españolas en los foros internacionales fueron reducidas, dadas las limitaciones impuestas por el modelo de género y su cualificación autodidacta, más baja que la de sus homólogos masculinos. De todas maneras, es necesario seguir rastreando sus aportaciones en esos foros a lo largo del período de entreguerras.

\footnotetext{
69 GARCÍA, 1952: 81.
} 


\section{BIBLIOGRAFÍA}

Aguado, Ana, «Entre lo público y lo privado. Sufragio y divorcio en la II República», Ayer, República y republicanas, 60 (Madrid, 2005): 105-134.

Aroca, Manuela, «Spain’s Unión General de Trabajadores in the international context (1888-1936)», Ventunesimo Secolo, 38 (Roma, 2016): 9-33.

Berzal de la Rosa, Enrique, «More internationalism, more strength: the Unión General de Trabajadores in the International Labor Organization, 1919-1936», Ventunesimo Secolo, 38 (Roma, 2016): 34-57.

Capel, Rosa, «Mujer y socialismo (1848-1939)», Pasado y Memoria. Revista de Historia Contemporánea, 7 (Madrid, 2008): 101-122.

De la Torre, Matilde, «Las Cortes republicanas durante la Guerra Civil. Madrid 1936, Valencia 1937 y Barcelona 1938», Introducción y edición de Francisca Vilches de Frutos, Madrid, FCE, 2015.

Del Moral, Marta, «The women's socialist group of Madrid (1906-1927): (Re)defining citizenship for Spanish women», International Journal of Iberian Studies, 27/2-3 (2014): 203-218, Open Forum, doi: 10.1386/ijis.27.2-3.203_1.

Di Febo, Giuliana, «Isabel de Palencia. Una republicana en la Sociedad de Naciones», en Mary Nash (coord.), Ciudadanas y protagonistas históricas. Mujeres republicanas en la II República y la Guerra Civil, Madrid, Congreso de Diputados, 2009: 129-146.

Diccionario Biográfico del Socialismo español, http://www.fpabloiglesias.es/archivo$\mathrm{y}$-biblioteca/diccionario-biografico.

Domínguez, Pilar, De ciudadanas a exiliadas: un estudio sobre las republicanas españolas en México, Madrid, Fundación Largo Caballero/Cinca, 2009.

Domínguez, Pilar, «The Presence and Absence of Spanish Socialist Women in the International Trade Unions during the Interwar Period», Ventunesimo secolo, 38 (Roma, 2016): 58-77.

Eiroa, Matilde, Isabel de Palencia. Diplomacia, periodismo y militancia al servicio de la República, Málaga, Universidad de Málaga, 2014.

García, Regina, Yo he sido marxista. El cómo y el porqué de una conversión, Madrid, Ed. Nacional, 1952.

Jacques, Catherine, «Des lobbys féministes à la SDN: l'exemple des débats sur la nationalité de la femme mariée (1930-1935)», en Jean-Marc Delaunay et Yves Denechère, Femmes et relations internationales au XXe siecle, Paris, Presses Sorbonne nouvelle, 2006: 267-277.

Jacques, Catherine, «Le féminisme en Belgique de la fin du 19e siècle aux années 1970», Cahier Hebdomaire du CRISP, 7 (Bruselles, 2009), https://www.cairn.info/ revue-courrier-hebdomadaire-du-crisp-2009-7-page-5-54.htm.

Nash, Mary, Rojas. Las mujeres republicanas en la Guerra Civil, Madrid, Taurus, 1999.

Nielfa, Gloria, «Trabajo, legislación y género en la España contemporánea: los orígenes de la legislación laboral», en Lina Gálvez y Carmen Sarasúa (coords.), 
¿Privilegios o eficiencia?: mujeres y hombres en los mercados de trabajo, Alicante, Universidad de Alicante, 2003: 39-56.

Paz, Olga, Isabel Oyarzábal Smith (1878- 1974). Una intelectual de la Segunda República. Del reto del discurso a los surcos del exilio, Sevilla, Junta de Andalucía, 2010.

Van Goethem, Geert, The Amsterdam International; The World of the International Federation of Trade Unions (IFTU), 1913-1945, Aldershot, Ashgate, 2006a.

Van Goethem, Geert, «Protection ou egalité. Les femmes dans le mouvement syndical international (1919-1938)», en Jean-Marc Delaunay et Yves Denechère, Femmes et relations internationales au XXe siecle, Paris, Sorbonne, 2006b: 279-291.

Vilanova, Mercedes y Moreno, Xavier, Atlas de la evolución del analfabetismo en España, 1887-1981, Madrid, CIDE, 1992.

Vilches de Frutos, Francisca, «Introducción», en Matilde De la Torre, Las Cortes republicanas durante la Guerra Civil. Madrid 1936, Valencia 1937 y Barcelona 1938, Madrid, FCE, 2015: 9-57.

Recibido: $19 / 12 / 2016$

Aceptado: 09/05/2018 